Social control policies and global justice. The border as an intersectional device for the production of injustices

\title{
Politicas de control social y justicia global. La frontera como dispositivo interseccional de producción de injusticias
}

Francisco Blanco Brotons

CSIC. Instituto de Filosofía

franciscojose.blanco@cchs.csic.es

DOI: https://doi.org/10.15366/bp2019.22.009

Bajo Palabra. II Época. № 22. Pgs: 189-202

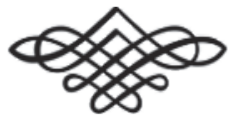


Recibido: 10/11/2017

Aprobado: 02/10/2019

\section{Resumen}

En este artículo se analizarán tres dinámicas de injusticia que caracterizan el papel de las fronteras amuralladas en nuestro mundo contemporáneo. Este análisis se realizará a través de una crítica del concepto de "tierra de nadie" que, como se defenderá, sirve para ocultar los mecanismos de control social que se ponen en funcionamiento a través de estos dispositivos, así como los agentes involucrados en ellos. Estas dinámicas serán sistematizadas, de acuerdo con el marco analítico propuesto por Nancy Fraser, distinguiendo la distribución, el reconocimiento y la dominación.

Palabras clave: globalización, fronteras, control social, injusticias.

\section{Abstract}

This paper will analyze three dynamics of injustice that characterize the role of walled borders in our contemporary world. This analysis will be carried out through a critique of the concept of "no man's land" which, as it will be defended, serves to hide the mechanisms of social control that are put into operation through these devices, as well as the agents involved in them. These dynamics will be systematized, according to the analytical framework proposed by Nancy Fraser, distinguishing distribution, recognition and domination.

Keywords: globalization, borders, social control, injustices. 
U sando una terminología fraseriana, las fronteras son un fenómeno en el que intersecan prototípicamente las dimensiones de dominación, de distribución y de reconocimiento. Frente a las perspectivas sobre interseccionalidad que utilizan esta categoría principalmente para analizar dinámicas de la política de identidad y de reconocimiento, en la línea de lo que Yuval-Davis denomina politics of belongings 1 , la perspectiva de Fraser $^{2}$ me parece que tiene la virtud de ofrecer una marco teórico de mayor escala, al ańadir a las cuestiones identitarias y de reconocimiento, las dimensiones de dominación y de producción y distribución capitalista. Las complejidades de lo global nos fuerzan a una reconceptualización y ampliación de la noción de sistema social, para el que en paralelo debe desarrollarse un marco normativo capaz de visibilizar las múltiples dimensiones de desigualdad a través de las que se desarrollan e interconectan sistemas sociales crecientemente complejos, cambiantes y flexibles. De este modo, la perspectiva interseccional puede superar el peligro de reduccionismo contra el que alertan Walby, Armstrong y $\operatorname{Strid}^{3}$ y atender cuestiones de mayor escala que involucren un horizonte global, tal como reclama Benhabib ${ }^{4}$. Las fronteras, en tanto que dispositivos importantes dentro de estructuras sociales enormemente complejas que ya tienen alcance planetario, son una de estas cuestiones de mayor escala que demandan una perspectiva interseccional ampliada.

Las categorías analíticas que aplicamos para describir o analizar los fenómenos del mundo contemporáneos son muy relevantes y su análisis puede reflejar la intersección de diversas dinámicas de injusticia. Por este motivo, este artículo atiende al creciente uso que nuestros gobiernos hacen del concepto de tierra de nadie para describir nuestras fronteras amuralladas. ¿Es ese concepto aplicable a este fenóme-

\footnotetext{
Este artículo se ha elaborado en el marco de un proyecto de investigación financiado por el Ministerio de Economía y Competitividad: "Derechos humanos y justicia global en el contexto de las migraciones internacionales» (FFI2013-42521-P).

${ }^{1}$ Yuval-Davis, N., Intersectionality, Citizenship and Contemporary Politics of Belonging, Critical Review of International Social and Political Philosophy, n.10, vol. 4, 2007, pp. 561-574. Ver también Yuval-Davis, N. Power, Intersectionality and the Politics of Belonging, FREIA Working Paper Series, n. 75, 2011, pp. 1-16.

${ }^{2}$ Fraser, N., Escalas de justicia (Traducción de A. Martínez Riu), Barcelona, Herder, 2008.

3 Walby, S; Armstrong, J; Strid, S., Intersectionality: Multiple Inequalities in Social Theory, Sociology, n. 46, vol. 2, pp. 224-240.

${ }^{4}$ Benhabib, S., Sexual Differences and Collective Identities: The new Global Constellation, Singns, n. 24, vol. 2, 1999, pp. 335-361.
} 
no? ¿Es una aceptable descripción de la realidad? ¿Qué nos indica su creciente uso? ¿Con qué intenciones se emplea? ¿Se emplea con la intención de ocultar injusticias? En este último caso, su puesta en cuestión nos permitiría hacer visibles estas injusticias. En este texto se defiende que el uso del concepto de tierra de nadie en este contexto oculta diversos mecanismos que operan en las fronteras y que favorecen el desarrollo de diversas injusticias. El objetivo de este artículo es precisamente denunciar el uso espurio del concepto de tierra de nadie que se hace al aplicarlo a las fronteras amuralladas y visibilizar algunas de las dinámicas interseccionales de injusticia que estas fronteras ponen en funcionamiento.

Tal como Antonio Campillo nos explica en su libro Tierra de nadie. Cómo pensar (en) la sociedad global 5, la aplicación del concepto de tierra de nadie a las fronteras amuralladas es un uso característico y creciente que nuestro mundo contemporáneo hace de este concepto. Sin embargo, no debemos simplemente constatar este hecho, como Campillo hace en su libro, sino analizarlo, criticarlo y juzgarlo, para visibilizar las injusticias que su empleo pudiese ocultar. Para ello debemos cuestionar si este término constituye una adecuada descripción de las fronteras amuralladas y, si este no es el caso, preguntarnos con qué finalidad se aplica este término descriptivamente erróneo. De aquí proviene el título de este artículo, pues aquí se pretende mostrar que se trata de un término erróneo, pero que su errónea aplicación nos dice algo que debe ser denunciado. Para esta visibilización propongo guiarnos por el análisis que Wendy Brown hace de las fronteras amuralladas en Estados amurallados, soberanía en declive 6 , donde nos muestra que en sus dimensiones psicológicas, identitarias y políticas, el empleo del concepto de tierra de nadie en este contexto es un error categorial con claras intenciones, precisamente las de ocultar injusticias que surgen en la intersección de las dimensiones política, de reconocimiento y de distribución (aquí se prestará mayor atención a las dimensiones política y de reconocimiento, ya que generalmente se dejan más de lado en las cuestiones fronterizas, sobre todo por el peso que las injusticias de distribución adquieren en nuestro sistema internacional).

Según Antonio Campillo, "Res nullius" o "terra nullius" eran originalmente dos de los diversos conceptos con los que estaba equipado el derecho romano para organizar el conjunto de cosas susceptibles de apropiación y transmisión. Campillo repasa cinco usos de este concepto surgidos a lo largo de su evolución histórica: (1) "tierra que no tiene dueño porque nadie la ha reclamado todavía"; (2) "tierra de ultramar habitada por pueblos 'salvajes' y, por lo tanto, susceptible de ocupación

\footnotetext{
${ }^{5}$ Campillo A., Tierra de nadie. Cómo pensar (en) la sociedad global, Barcelona, Herder, 2015.

${ }^{6}$ Brown, W., Estados amurallados, soberanía en declive (traducción de A. Martínez Riu), Barcelona, Herder, 2015.
} 
por algún estado europeo 'civilizado"'; (3) "la tierra fronteriza que es disputada por dos estados vecinos"; (4) "la tierra fronteriza entre dos estados vecinos que es amurallada por uno de ellos para evitar el libre tránsito de personas"; (5) "la tierra que es declarada "patrimonio común de la humanidad" y de la que se excluye cualquier reclamación territorial por parte de nadie" 7 . Según Campillo, el primer significado era el que aparecía en el derecho romano, los dos siguientes eran los empleados por las potencias europeas durante el período colonial, mientras que los dos últimos usos aparecen con el proceso de globalización en el cual nos encontramos inmersos.

Los tres primeros usos tienen ya un papel muy cuestionable en el mundo actual. Respecto al primero, todo el planeta ya se encuentra repartido entre diversos estados. En cuanto al segundo, el concepto de tierra de nadie ya ha sido abandonado como instrumento del derecho internacional para justificar la ocupación de territorios habitados por gentes no europeas. Finalmente, respecto al tercero, los conflictos fronterizos entre dos estados no afirman que esa tierra no sea de nadie. Por ello, Campillo centra el potencial que este concepto nos aporta para comprender el nomos de nuestro mundo actual en los dos últimos usos, siendo el cuarto de los que acabo de indicar el que aquí nos interesa (la de tierra fronteriza amurallada).

Respecto a las murallas fronterizas, Campillo constata su proliferación y sus consecuencias en cuanto a muertes y sufrimiento, también señala la paradoja que se da entre estas murallas, cuya finalidad es impedir el flujo de personas migrantes, y la actual dinámica neoliberal que promueve la movilidad. Esta paradoja tendría por efecto aumentar la desigualdad económica, social y cultural, creando los nadie sin tierra, refugiados y desplazados sin derechos. Campillo pasa rápidamente del concepto tierra de nadie al de los nadie sin tierra, sin mostrar la conexión entre ambas ideas, como si un simple juego de palabras instaurase por sí mismo esta conexión. En el análisis que Campillo hace de esta globalización amurallada se pierde el objeto del libro, es decir, este autor no justifica ni aclara en qué sentido esta política de fronteras se comprende de un modo productivo a través de la aplicación del concepto de tierra de nadie o por qué, al fin y al cabo, se aplica este concepto a ese fenómeno.

Las fronteras amuralladas son complejos dispositivos de control para, entre otras cosas, impedir la libre circulación de personas. Dispositivos que crean, debido al contexto neoliberal, un aumento de la desigualdad y de la explotación. ¿Qué tiene esto de tierra de nadie? Tampoco los nadie sin tierra son meros productos de estas vallas fronterizas, sino de todo un complejo sistema de regulación de fronteras, de relaciones interestatales y trasnacionales y de un sistema económico mundial. ¿¿De

7 Campillo, A, Tierra de nadie. Cómo pensar (en) la sociedad global, op. cit., pp. 35-37. 
qué modo el concepto de tierra de nadie, objeto del libro de Campillo, aporta luz sobre estas dinámicas? El libro de Campillo no nos da ninguna de estas respuestas, que son, sin embargo, fundamentales para comprender y evaluar el concepto que es objeto de su libro. Para dar una respuesta a esta pregunta propongo acudir a Estados amurallados, soberanía en declive de Wendy Brown.

Brown se centra en el fenómeno del amurallamiento de fronteras porque según ella este fenómeno puede ayudarnos a comprender algunas características del actual orden globalizado y de nosotros mismos, de la psicología que hay detrás de esta política global. Es decir, su análisis adopta el mismo objetivo que tenía Campillo, esto es, ayudarnos a pensar y comprender la organización de la sociedad global.

Según Brown, las fronteras amuralladas no manifiestan, como sus constructores pretenden, el gran poder del Estado, sino su debilidad para controlar los nuevos flujos trasnacionales en el nuevo terreno de interrelaciones globalizadas. Aún más, los muros no son sólo artefactos que pretenden hacer frente a los cruces fronterizos irregulares, sino que son elementos simbólicos de poder al servicio del Estado y de sus ciudadanos. Además de aportar alguna luz sobre las nuevas realidades trasnacionales que erosionan el poder del Estado, del análisis de estas dinámicas fronterizas Wendy Brown extrae también interesantes consideraciones sobre psicología política. Esta autora nos muestra cómo funciona una dimensión frecuentemente olvidada de lo político, esto es, su dimensión simbólica o imaginativa (una dimensión, vale la pena decirlo, nunca olvidada por los seguidores de Carl Schmitt). La política no es una mera cuestión funcional, y los muros fronterizos muestran esta verdad en toda su crudeza: no pueden cumplir con la función para la que supuestamente se construyen, controlar estrictamente el tránsito de personas, pero restituyen a los Estados modernos una apariencia de dignidad y poder soberanos que no es necesitada solamente por los gobiernos, sino sobre todo por sus ciudadanos, para poder seguir viviendo en la necesaria ilusión de orden, control y seguridad, así como de identidad individual y nacional. Los muros, además, invierten la relación simbólica entre el dominador y el subordinado, al representarse como protecciones que una población vulnerable e inocente necesita ante la amenaza ubicua e informe de los flujos trasnacionales.

Las fronteras no son "tierras de nadie" puesto que guardan una estrecha relación con sus protegidos, los cuales poseen íntimamente y son simultáneamente poseídos por sus fronteras. Creo que podemos analizar esta posesión según tres dinámicas estrechamente interrelacionadas, separables sólo analíticamente, que denominaré dinámicas económicas de producción y distribución, dinámicas psicológicas de representación de sí mismos y del otro y dinámicas de dominación. 


\section{Dinámicas económicas de producción y distribución}

LAS FRONTERAS AMURALLADAS tienen un importante papel en el sistema económico global. Son un dispositivo más de este sistema. Por ello, dado que este sistema es un frecuente objeto de análisis, estas dinámicas recibirán menos atención en este texto. El problema aquí no es simplemente, como Campillo cree, que estas fronteras, supuestamente movidas por una lógica nacionalista, sean contradictoras con la dinámica aperturista de la globalización neoliberal. Todo lo contrario, las fronteras amuralladas tienen un papel muy significativo dentro de este sistema, especialmente en la constitución de la fuerza de trabajo flexible y heterogénea que el capitalismo de la actual fase de la globalización precisa. Como nos explica Brown, al hacer que la inmigración sea más difícil y costosa, aumenta la migración unidireccional y se reduce el retorno de los inmigrantes ilegales ${ }^{8}$, lo que les fuerza a permanecer en sus nuevos países en una situación precaria que tiene como efecto abaratar su mano de obra para trabajos cada vez más precarios, es decir, se les convierte en víctimas de una mayor y más fácil explotación que en el caso de que pudieran volver a sus países de origen y entrar en los de acogida con mayor flexibilidad. Por todo ello, como nos dice Juan Carlos Velasco, parecería que las fronteras amuralladas "no persiguen tanto ordenar las migraciones de la gente como optimizar los mecanismos de explotación de los trabajadores trasnacionales"'.

En un contexto en globalización en el que las dinámicas económicas trascienden ampliamente el marco del Estado-nación, en el que los modos de producción, las relaciones laborales y los tiempos y espacios del capitalismo global se complejizan y flexibilizan enormemente, la proliferación y complejización que muestran los mecanismos fronterizos corren paralelos a las necesidades sistémicas del capitalismo globalizado actual. No es casual que las fronteras territoriales dejen de entenderse como simples líneas y pasen a comprenderse más como complejos enclaves, dispositivos o zonas territoriales. Hoy las fronteras estatales están constituidas por terribles muros, sin duda, pero también por centros de internamiento, áreas desmilitarizadas, áreas francas, zonas económicas especiales, etc. Los dispositivos fronterizos proliferan y se diversifican para general la diversidad de fuerza de trabajo, de tiempos, ritmos, prácticas y de normas regulatorias que exigen unos procesos de producción capitalista que "están organizados en redes híbridas y flexibles que se extienden a lo largo de terrenos globales cada vez más diferenciados" ${ }^{10}$. Los dispo-

\footnotetext{
${ }^{8}$ Brown, W., Estados amurallados, soberania en declive op. cit., pp. 133-134.

9 Velasco, J. C., El control de las fronteras y la justicia distributiva en un mundo globalizado, en F. Arcos Ramírez (Ed.), La justicia y los derechos en un mundo globalizado, Madrid, Dykinson, 2015, p. 63.

${ }_{10}$ Mezzadra, S.; Neilson, B., La frontera como método, Madrid, Traficantes de Sueños, 2017, p. 88.
} 
sitivos fronterizos amurallados actuales no tienen nada de "tierra de nadie" ni de contradictorio con las dinámicas neoliberales actuales, todo lo contrario, son otro de los diversos sistemas de dispositivos que posibilitan, favorecen y conforman estas dinámicas, profundamente embebidos en ellas. Los dispositivos fronterizos son una pieza más de la compleja ontología de la estructura capitalista del mundo actual.

\section{Dinámicas psicológicas de representación}

Estos MUROS SON HERRAMIENTAS SIMBÓLICAS que ayudan a constituir las identidades nacionales de sus protegidos. Tienen profundos efectos sobre el bienestar psicológico de algunos sujetos políticos y sobre la autorrepresentación de los agentes soberanos estatales. Frente a la crisis de la soberanía en el mundo globalizado, frente a la menguante capacidad de los Estados para controlar los flujos trasnacionales y el creciente protagonismo a nivel global de otros agentes no estatales, el deseo popular de levantar muros, según Brown, "alberga un ansia de poderes de protección, contención e integración prometidos por la soberanía" ${ }^{11}$. Del mismo modo son una reacción contra el peligro que la crisis de la soberanía que provoca la globalización actual tiene para la identidad nacional, pues "la desvinculación de la potestad soberana de los Estados nación amenaza también a un imaginario de identidad individual y nacional que depende de la percepción de horizontes y de la contención que ofrecen" ${ }^{12}$. La forma como una comunidad gestiona sus límites, el modo como constituyen sus identidades colectivas e individuales, así como la aspiración a la soberanía plena de la comunidad política se encuentran, según Brown, estrechamente conectadas:

"Todos los muros que definen o defienden entidades políticas han configurado la identidad colectiva e individual en el interior tanto como han pretendido interceptar toda penetración desde el exterior (...) Inadvertidamente producen un ethos y una subjetividad colectivos, defensivos, cortos de miras, nacionalistas y militarizados. Generan una identidad colectiva cada vez más cerrada y vigilada, en lugar de la sociedad abierta que pretenderían defender" ${ }^{13}$.

Los muros responden tanto a la necesidad psicológica de protección como a la elaboración de la identidad individual y nacional, pero la tesis principal de Brown es que el significado de los muros en estas dinámicas no es funcional (respecto a su función explícita de contención de la migración) sino simbólico: realmente no

\footnotetext{
11 Brown, W., Estados amurallados, soberanía en declive, op. cit., p. 35.

12 Ibid., p. 37.

${ }^{13}$ Ibid., pp. 58-59.
} 
controlan los flujos, no imponen el orden ni protegen, simplemente lo escenifican (son un elemento central, recordando a Castoriadis, de la "institución imaginaria de la sociedad" contemporánea). Su función es intentar representar una ya irreal separación estricta entre un adentro de ciudadanos nacionales homogéneos, autosuficientes y unidos por una cultura política común, y un afuera de agentes extraños y amenazantes con los que no se tendría nada en común ${ }^{14}$.

¿Qué se gana desde esta perspectiva considerando las fronteras como tierra de nadie? Las fronteras pertenecen íntimamente a la autoconstitución simbólica de sus protegidos y de sus Estados protectores, poseen y son poseídos en una estrecha dialéctica representacional e identitaria. Tienen un papel fundamental en la constitución subjetiva de las personas, en su comprensión de sí mismas y del mundo. Estas fronteras amuralladas son íntimamente de alguien, por lo que conceptualizarlas como tierra de nadie tiene por finalidad ocultar esta conexión entre lo escenográfico y la constitución de los agentes políticos, viendo como real y originario lo que no es sino simbólico y representacional. Así, el poder soberano pleno e intocable del Estado manifestado en el amurallamiento fronterizo sería una realidad, no una mera representación, y el orden, el control y la seguridad, así como la identidad inocente de sujetos amenazados, no serían una ilusión generada por estos dispositivos, sino una realidad previa que debe ser salvaguardada.

Desde el punto de vista de los gobiernos se gana mucho al categorizar estos dispositivos fronterizos como tierra de nadie, pues es de su interés ocultar estas dinámicas simbólicas y hacer ver como real lo que no son sino escenografías, hacer pasar como real lo que no es sino simbólico. Las fronteras amuralladas "disimulan el declive de la soberanía estatal escenificando su integridad y su poder, rompen la realidad de la interdependencia global y el desorden global escenificando la integridad, la autonomía y la autosuficiencia de la nación" ${ }^{15}$, es decir, ocultan las interdependencias del sistema global y las dinámicas de explotación del orden neoliberal. Al escenificar la autosuficiencia de la nación representan lo que Pogge llama el "nacionalismo explicativo" 16 como la realidad del orden global, ocultando que el nuevo orden de soberanía en el mundo globalizado va más allá de las unidades nacionales, absolviendo y colocando más allá del análisis crítico a las corporaciones trasnacionales y a las regulaciones neoliberales a las que se someten los gobiernos, así como las responsabilidades de algunas naciones en la miseria de otras. "La actividad amuralladora", nos dice Brown, debido a esta dinámica retorcida de reconocimiento en la que los

\footnotetext{
${ }_{14}$ Mezzadra, S.; Neilson, B., La frontera como método, op. cit., p. 12.

15 Brown, W., Estados amurallados, soberanía en declive, op. cit., p. 153.

${ }^{16}$ Pogge, T., La pobreza en el mundo y los derechos humanos (traducción de E. Weikert García), Barcelona, Paidós, 2005.
} 
dominadores son presentados como víctimas a las que proteger, "evita literalmente enfrentarse a la desigualdad global o a la dominación colonial local. Tiende a negar la dependencia de los privilegiados respecto de los explotados y que es precisamente la actuación del dominador lo que produce la resistencia de los oprimidos" ${ }^{17}$. La retórica de las fronteras amuralladas y de la tierra de nadie se opone a la justicia global, dando rienda suelta a chovinismos nacionalistas por parte de los países más beneficiados por el orden global. Por lo tanto, analizar las aplicaciones de tierra de nadie en este contexto supone denunciar su uso espurio, interesado en ocultar las dinámicas simbólicas del juego del poder globalizado.

\section{Dinámicas de dominación}

Estos MUROS NO SON UNA MERA BARRERA FÍsICA, sino que, al ser complejos dispositivos ideados y controlados por los Estados, al servicio de sus intereses particulares, entrañan "dinámicas de dominación" que les permiten la suspensión de las garantías legales que al menos formalmente imperan al interior de los amplios espacios fortificados. Estos muros ponen en juego "la suspensión literal de la ley, la responsabilidad y la legitimación, así como la introducción de una prerrogativa estatal arbitraria y al margen de la ley que hace acto de presencia en situaciones de emergencia" ${ }^{18}$. Estos muros van más allá de su mero carácter físico y se constituyen en situaciones en las que no hay ley, situaciones de violencia que responden a estados de emergencia.

Nuestros Estados se empeñan en describir las amplias zonas fronterizas como tierra de nadie, tierras que no pertenecen plenamente a ninguna de las soberanías colindantes, por lo que no impera en ellas el "Estado de Derecho" característico del moderno poder estatal. ¿Podríamos aceptar que al menos aquí, para esta dimensión de "suspensión de garantías legales", tendría algún sentido no espurio la aplicación a las fronteras del término tierra de nadie? Podría parecer que sí, pues en un territorio sin ley todos perderíamos nuestra condición de persona, de agentes protegidos por derechos, y así sería una tierra de nadies anónimos en los que todos ven igualmente negados sus derechos, su individualidad y hasta su identidad personal. Lamentablemente vemos todos los días en nuestros televisores noticias sobre esos sufrientes migrantes que no pueden recurrir a ninguna ley o a ningún agente soberano que los proteja. Parecería, finalmente, que "tierra de nadie" es aquí una etiqueta apropiada, una etiqueta que describiría adecuadamente la realidad.

\footnotetext{
${ }_{17}$ Brown, W., Estados amurallados, soberania en declive, op. cit., p. 178.

18 Ibid., p. 45.
} 
Sin embargo, fácilmente se puede hacer ver lo falso de esta conclusión. La interpretación de las fronteras como tierra de nadie obra a favor de la dinámica del poder, ocultando algunas de sus características importantes. Que las fronteras amuralladas generen entornos que crean algunos "nadies" sin derechos es muy diferente a decir que estas fronteras en sí son "tierras de nadie", pues ni todos los agentes implicados en el funcionamiento de estos dispositivos son "nadies", ni las fronteras en sí son meros residuos no intencionales de dinámicas independientes, al modo de situaciones de nadie sobre las que ningún agente tenga control explícito o responsabilidad directa. Defender esto último sería caer en el naturalismo no-intencional neoliberal que tanto Campillo como Brown condenan, pero que tanto favorece, precisamente mediante su ocultamiento, al ejercicio del poder opresor de algunos gobiernos.

Las fronteras son dispositivos diseñados por agentes concretos, con el apoyo explícito e incluso con la colaboración activa de ciudadanos particulares ${ }^{19}$, que responden a intereses concretos y políticas específicas de estos agentes. Como ya se ha dicho, los dispositivos fronterizos tienen un papel fundamental en la creación de una fuerza de trabajo heterogénea y flexible. Algunos de sus elementos, como los centros de internamiento, pueden incluso interpretarse como dispositivos que intencionalmente controlan el tiempo y la velocidad de la introducción de fuerza de trabajo en el mercado ${ }^{20}$. Por otro lado, desde el punto de vista de los derechos formales aplicables, al menos para las democracias constitucionales las líneas que separan dos Estados son líneas geométricas sin espesor, definidas con precisión, de modo que siempre deberían de quedar claro los derechos aplicables a todos en cada fracción de terreno. Postular tierras de nadie donde los derechos quedan suspendidos es una vulneración evidente de las garantías legales que supuestamente deberían aplicarse en todo el territorio estatal. Dado que la tierra que ocupan los dispositivos fronterizos tienen en todos los sentidos rigurosos poseedores, organizadores y responsables, aplicar a estos dispositivos el concepto de "tierra de nadie" es absolverlos de las graves responsabilidades que estos agentes tienen en las muertes de miles de personas y en los agudos sufrimientos de muchos más. Es cegarnos ante las intencionalidades y la agencia que fundamentan estos amurallamientos fronterizos.

En muchos terrenos, los Estados tienen interés en ocultar o descargarse de responsabilidades. La privatización o externalización del los dispositivos de control tienen un papel clave en el logro de este objetivo. Teóricamente se debe evitar caer

\footnotetext{
${ }_{19}$ En este sentido, la descripción que realiza Brown sobre la participación en el control de las fronteras de los ciudadanos residentes en los territorios estadounidenses limítrofes con la frontera mexicana, formando patrullas armadas y presionando a sus representantes políticos para que endurezcan las medidas de control, resulta muy ilustrativo.

${ }^{20}$ Mezzadra, S.; Neilson, B., La frontera como método, op. cit., p. 158.
} 
en la trampa de algunos discursos que obran a favor de estos intereses. Mezzadra y Neilson, siguiendo a Teubner, constatan una "fragmentación de la normatividad" y la creciente relevancia de la normatividad decidida por empresas privadas, lo cual implicaría reconocer "que las soluciones normativas no se derivan necesariamente del derecho formal" ${ }^{21}$. En algunos dominios el imperio de la ley habría sido profundamente debilitado y la capacidad del Estado sería limitada o incluso inexistente. Esta retórica tiene el peligro de ocultar el papel de los Estados en la cesión de ámbitos de control y de decisión para tener otros agentes no sujetos a escrutinio público sobre los que descargar las responsabilidades. Si los Estados parecen retirarse del control de algunos ámbitos es porque ellos así lo han permitido ${ }^{22}$. Esta retórica de la normativa privada como una fuente de ley independiente de la fuente Estatal ignora que la soberanía estatal sigue siendo un marco estructurante y limitador fundamental. Esas empresas privadas no constituyen una fuente de ley autónoma, deben seguir adaptando sus normativas internas a las leyes nacionales donde operan.

Aplicar el concepto de tierra de nadie a nuestras fronteras amuralladas responde a una peculiar transformación del régimen fronterizo: la transformación del borderline en borderland. Se nos pretende ocultar que las fronteras son líneas que marcan con precisión dónde comienza nuestro Estado de Derecho, y los gobiernos amuralladores nos pretenden imponer la idea de que éstas son franjas de tierra delimitadas por diversas verjas que no pertenen a ningún Estado concreto, por lo que en ellas no habría leyes ni derechos. Este nuevo régimen fronterizo, según Juan Carlos Velasco,

\begin{abstract}
"pretende proporcionar cobertura legal a la externalización de los controles fronterizos y sortear la obligatoriedad de garantizar los derechos humanos. La ficción de un espacio fronterizo de soberanía indiferenciada -que vaya más allá del trazado de una línea- no es más que una insostenible ficción jurídica que no resiste en más mínimo examen crítico. Como norma general, no existen tierras de nadie en donde los individuos que las pretenden franquear queden desprovistos de derechos" ${ }^{23}$.
\end{abstract}

\title{
4. Conclusión.
}

El anÁlisis por SEPARAdo de estas tres dimensiones nos lleva a la misma conclusión: no hay «tierras de nadie» fronterizas como tampoco hay nadies sin derechos. Lo que hay en su lugar son vulneraciones flagrantes de las leyes y de los derechos

\footnotetext{
21 Ibid., p. 215.

22 Sassen, S, The Participation of States and Citizens in Global Governance. Indiana Journal of Global Legal Studies, n.10, vol.1, 2003, pp. 7-16.

23 Velasco, J. C., El control de las fronteras y la justicia distributiva en un mundo globalizado, op. cit., p. 54.
} 
humanos, cuando las fuerzas de control fronterizo practican "devoluciones en caliente", rocían con gas lacrimógeno a personas situadas en las inmediaciones de las vallas, cuando se impide a los trabajadores indocumentados el regreso a sus casas para para optimizar la explotación laboral a la que se encuentran sujetos, o cuanto las sociedades amuralladas nos autojustificamos invirtiendo la relación entre el culpable y la víctima y nos negamos a ver el orden global de dominación y explotación.

Aplicar el concepto de tierra de nadie al contexto generado por las dinámicas que hemos aquí bosquejado es una clara aplicación espuria de una idea con el objeto de ocultar injusticias en beneficio de los estados más poderosos y de los ciudadanos injustamente beneficiados. 


\section{Referencias Bibliográficas}

Benhabib, S., Sexual Differences and Collective Identities: The new Global Constellation, Singns, n. 24, vol. 2, 1999, pp. 335-361. doi: 10.1086/495343

Brown, W., Estados amurallados, soberania en declive (traducción de A. Martínez Riu), Barcelona, Herder, 2015.

Campillo A., Tierra de nadie. Cómo pensar (en) la sociedad global, Barcelona, Herder, 2015.

Fraser, N., Escalas de justicia (Traducción de A. Martínez Riu), Barcelona, Herder, 2008.

Mezzadra, S.; Neilson, B., La frontera como método (V. Hendel, Trans.), Madrid, Traficantes de sueños, 2017.

Pogge, T., La pobreza en el mundo y los derechos humanos (traducción de E. Weikert García), Barcelona, Paidós, 2005.

Sassen, S., The Participation of States and Citizens in Global Governance, Indiana Journal of Global Legal Studies, n. 10, vol. 1, 2003, pp. 5-28. doi: 10.2979/ gls.2003.10.1.5

Velasco, J. C., El control de las fronteras y la justicia distributiva en un mundo globalizado, en F. Arcos Ramírez (Ed.), La justicia y los derechos en un mundo globalizado, Madrid, Dykinson, 2015, pp. 49-74.

Walby, S., Armstrong, J.; Strid, S., Intersectionality: Multiple Inequalities in Social Theory, Sociology, n. 46, vol. 2, 2012, pp. 224-240. doi: $10.1177 / 0038038511416164$

Yuval-Davis, N., Intersectionality, Citizenship and Contemporary Politics of Belonging, Critical Review of International Social and Political Philosophy, n.10, vol. 4, 2007, pp. 561-574. doi: 10.1080/13698230701660220.

Yuval-Davis, N. Power, Intersectionality and the Politics of Belonging, FREIA Working Paper Series, n. 75, 2011, pp. 1-16. 